Original Research Paper

\title{
Penyuluhan Kesehatan Penanganan Nyeri Punggung Bawah (Low Back Pain) di Krakitan Bayat Klaten
}

\author{
Amalia Solichati Rizqi ${ }^{1}$, Yudha Wahyu Putra ${ }^{2}$ \\ ${ }^{12}$ Program Studi Fisioterapi, Universitas Widya Dharma Klaten ${ }^{2}$
}

https://doi.org/10.29303/jpmpi.v3i2.935

Sitasi: Rizqi, A. S., \& Putra, Y. W. (2021). Penyuluhan Kesehatan Penanganan Nyeri Punggung Bawah (Low Back

Pain) di Krakitan Bayat Klaten. Jurnal Pengabdian Magister Pendidikan IPA, 4(3)

\section{Article history}

Received: 31 Juli 2021

Revised: 30 Agustus 2020

Accepted: 2 September 2021

*Corresponding Author:

Amalia Solichati Rizqi.

Program Studi Fisioterapi,

Universitas Widya Dharma

Klaten

Email:

amaliasolichati@gmail.com

\begin{abstract}
Nyeri punggung bawah adalah rasa tidak nyaman yang dapat menimbulkan berbagai macam gangguan yang dapat mengakibatkan masalah pada kehidupan manusia khususnya masalah kesehatan. Tujuan dalam pengabdian ini adalah memberikan pengetahuan untuk diterapkan dalam masyarakat agar dapar mencegah dan menangani nyeri punggung bawah. Metode dalam pengabdian ini adalah dengan cara memberikan penyuluhan secara 1;angsung kepada masyarakat terkait cara mencegah dan menangani nyeri punggung bawah. Hasil dari pengabdian adalah terlaksanya kegiatan dengan baik dengan peserta sejumlah 60 orang. Kesimpulan. Nyeri punggung bawah bisa diatasi dengan memberikan penyuluhan dengan pengetahuan pencegahan dan penanganan secara dini
\end{abstract}

Keywords: Nyeri Punggung Bawah, Penyuluhan Kesehatan,

\section{Pendahuluan}

Industri di Indunesia dari tahun ke tahun semakin berkembang.. Gaya hidup modern yang dianut sebagaian besar masyarakat Indonesia sangat memungkinkan suatu gangguan penyakit,seperti aktivitas rutin dalam posisi duduk, berdiri, posisi jongkok yang terlalu lama, aktivitas-aktivitas yang berlebihan dengan posisi yang tidak sesuai dapat juga menjadi pemicu timbulnya berbagai macam keluhan nyeri di Desa Krakitan, Kecamatan Bayat, Kabupaten Klaten

Dalam menjalankan kehidupan sehari-hari setiap orang tidak akanlepas dari kebugaran jasmani, karena kebugaran jasmani merupakan salah satu faktor yang sangat penting dalam menjalankan kehidupan sehari -hari. Kebugaran jasmani terkait erat dengan keadaan kesehatan seseorang. Definisi sehat menurut organisasi kesehatan dunia (WHO) adalah "health is a state of physical, mental and social well being and not merely the absence of disease or infirmity. (Aprillia Krissanthy, Febi Kurniawan \& Citra Resita, 2020)

Nyeri dapat menimbulkan gangguan tidur, depresi, anoreksia, kehilangan berat badan, fatigue, dan terisolasi dari kehidupan sosial serta dapat menyebabkan gangguan dalam berpakaian, mandi, aktivitas sehari-hari, perjalanan,belanja, memasak dan pekerjaan rumah.Data klinis dan survei menunjukkan bahwa nyeri dapat mengganggu kualitas hidup pasien,terutama yang mengalami nyeri kronik. Gangguan kualitas hidup dapat berupa gangguan fungsional(menjadi tidak aktif), gangguan fisik, dan gangguan dalam interaksi sosial. (Wizar PM. 2019).

Nyeri merupakan perasaan tidak nyaman yang dialami manusia dan setiap manusia mempunyai nilai ambang nyeri yag berbeda,Pada dasarnya keluhan nyeri dapat terjadi pada bangunan neuromuskuloskeletal yang mana dari tubuh manusia, diantaranya nyeri pinggang bawah, dalam dunia medis disebut Low back pain. Dimana orang 
awam menyebutnya dengan sebutan sakit boyok, encok dan sebagainya. Berbagai macam bentuk keluhan di daerah ini dapat timbul karena kurang berhati-hati dan sikap yang kurang memperhatikan segi keamanan dalam beraktivitas. Nyeri punggung bawah atau lebih dikenal dengan Low back pain, merupakan salah satu keluhan yang sering dialami. Kasus nyeri yangpalingbanyak ditemui di rumah sakit adalah Nyeri Pinggang Bawah (NPB) atau Low back pain (LBP) (Putra \& Amalia, 2018). Pemberian exercise oleh fisioterapi merupakan salah satu penanganan nyeri yang bisa dilakukan ileh seorang fisioterapi ( Wardojo, et.al. 2020)

\section{Metode}

Metode kegiatan yang dilakukan untuk membantu memecahkan masalah dengan metode penyuluhan dan demonstrasi latihan dan pencegahan untuk mengatasi nyeri punggung bawah ( Low Back Pain ) menggunakan tekhnik terapi latihan William Flexion Exercise dan pencegahan law back pain dengan memperhatikan ergonomic dalam neraktifitaskepada masyarakat desa Krakitan

Kegiatan Pengabdian ini dilakukan dengan pemaparan presentasi tentang nyeri punggung bawah (Low Back Pain) kemudian dilanjutkan diskusi terkait permasalahan dan diakhiri dengan demonstrasi terapi latihan menggunakan William Flexion Exercise. Media yang digunakan dalam kegiatan ini adalah power point dan manual handling.Pencegahan permasalahan law back pain dalam masyarakat akan dilakukan dengan cara melaksanakan sosialisasi serta demonstrasi yaitu bagaimana posisi yang tepat dan dalam dalam berktifitas fisik, misalnya posisi duduk ke berdiri, posisi mengangkat barang dengan tepat, posisioning dalam berktivitas fisik

\section{Hasil dan Pembahasan}

Pelaksanaan pengabdian masyarakat ini diperoleh hasil yaitu kegiatan diawali dari dengan tahap persiapan yang terlaksanan dengan baik. Persiapan awal dalam pelaksanaan pengabdian masyarakat berupa koordinasi dengan dengan pemerintah desa Krakitan, Kecamatan Bayat, Kabupaten Klaten dan dilanjutkan dengan penyuluhan fisioterapi pada kelompok posyandu lansia pengajian yang dihadiri oleh 60 peserta yang dilaksanakan pada tanggal 15 Juni 2021di gedung pertemuan desa Krakitan, Kecamatan Bayat, Kabupaten Klaten

Penyuluhan dilakukan dengan tema khusus yaitu penanganan dan pencegahan nyeri punggung bawah dengan positioning yang benar serta pemberian ecxercise untuk menurunkan nyeri punggung bawah. Exercise dalam penanganan nyeri punggung bawah dapat di berikan dengan latihan menggunakan metode William flexi exercise. Latiahan William Flexy exercise efektif untuk menurunkan nyeri dan meningkatkan Lingkup gerak sendi (Amila, Henny S dan Evarina Sembiring, 2021). Herwant 2019 juga menyatakan bahwa latihan William flexor exercise yang diaplikasikan pada penderita LBP dapat menurunkan nyeri yang dirasakan

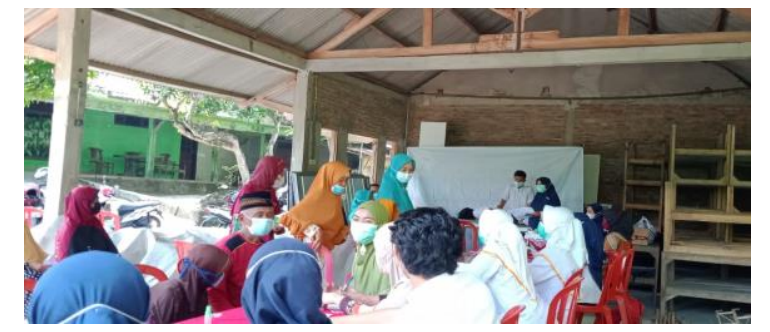

Gambar 1. Suasana Penyuluhan Kesehatan Penanganan Nyeri Punggung Bawah (Low Back Pain) Di Krakitan Bayat Klaten

Penyuluhan juga membahas tentang posisi posisi terkait atau yang dapat diaplikasikan oleh masyarakat terkait pemicu nyeri punggung bawah. Posisi tidur terlentang ke duduk yang benar yaitu saat seseorang tidur terlentang sebelum bangun maka terlebih dahulu harus miring ke kanan atau ke kiri kemuduan bangun. Saat mengangkat barang yang salah juga memicu nyeri punggung bawah. Mengangkat barang yang benar adalah dengan cara posisi duduk terlebih dahulu $\mathrm{b}$ aru berdiri.

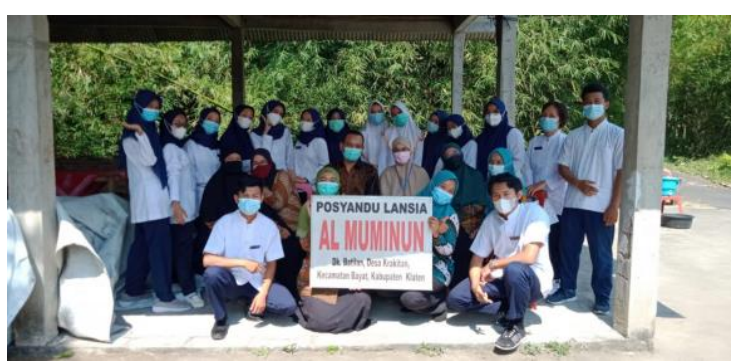

Gambar 2. Tim Penyuluhan Penyuluhan Kesehatan Penanganan Nyeri Punggung Bawah (Low Back Pain ) Di Krakitan Bayat Klaten 


\section{Kesimpulan}

Kegiatan pengabdian yang telah dilaksanankan dapat dimbil beberapa point kesimpulan

- Masyarakat mendapatkan pengetahuan yang sangat penting karena keluhan nyeri punggung bawah banyak terjadi kasus dalam masyarakat

Pencegahan nyeri punggung bawah dapat dhindari oleh masyarakat dengan adanya penyuluhan yang telah dilakukan

- Pengembangan kegiatan selannjutnya adalah sosialisasi - sosilisasi kegiatan serupa dengan tema kesehatan yang lain

\section{Saran}

Diharpakan pengabdian masyarakat ini bisa berjalan terus dan berkesinambungan dengan peserta yang lebih banyak serta materi - materi penyuluhan yang lebih banyak untuk peningkatan kesehatan dalam masyarakat

\section{Ucapan Terima Kasih}

Kepada segenaptim dan semua yang telah membantu terlaksananya kegiatan pengabdian kami mengucapkan terimakasihterutama pemerintah Desa Krakitan dan LembagaPengabdian Masyarakat Universitas Widya Dharma Klaten.

\section{Daftar Pustaka}

Aprillia Krissanthy, Febi Kurniawan, Citra Resita. 2020. Hubungan Kebugaran Jasmani dengan Tingkat Konsentrasi Siswa di SMA 9 Bekasi. Jurnal Literasi Olahraga. August 2020 no 1 (01) hal 77-81

Ida Bagus Ari Sudewa \& I Made Subagiartha,dr, SpAn.KAKV.,SH.2017. Efek Nyeri Terhadap Mutu Kehidupan.Bali. SMF/Bagian Anestesiologi Dan Reanimasi Fakultas Kedokteran Univesitas Udayana

RSUP Sanglah Denpasar

Putra, Y.W. and Rizqi, A.S., 2018. Index massa tubuh (IMT) mempengaruhi aktivitas remaja putri SMP Negeri 1 Sumberlawang. Gaster, 16(1), pp.105-115

Wizar Putri Mellaratna. 2019. Pengaruh Intensitas Nyeri Terhadap Kualitas
Hidup Pasien Post Herpetic Neuralgia. THESIS. Fakultas Kedokteran Universitas Sumatera Utara Medan

Wardojo, S.S.I., Rosadi, R., Amanati, S. and Putra, Y.W., 2020. EFEKTIFITAS MODALITAS LATIHAN TERHADAP PENURUNAN NYERI PADA LANSIA DENGAN OSTEOARTRITIS LUTUT DI KOTA MALANG. Physiotherapy Health Science (PhysioHS), 2(2), pp.39-49.

Amila, Amila, Henny Syapitri, and Evarina Sembiring.,2021 "The Effect of William Flexion Exercise on Reducing Pain Intensity For Elderly with Low Back

Pain." International Journal of Nursing and Health Services (IJNHS) 4.1: 28-36.

Harwanti, S. 2019. Pengaruh Latihan Peregangan (William Flexion Exercise) Terhadap Penurunan Low back pain Pada Pekerja Batik Tulis Di Desa Papringan Kecamatan Banyumas. Prosiding, 8(1) 